\title{
El ritual funerario durante la II E. del Hierro en la Península Ibérica. Algunas reflexiones sobre los grupos marginados por la investigación.
}

\author{
Lourdes PRADOS TORREIRA
}

\begin{abstract}
Resumen
Se plantea una aproximación al registro funerario durante la II Edad del Hierro en la P. Ibérica, en las necrópolis celtibéricas, vettonas y vacceas, haciendo hincapié en los enterramientos femeninos e infantiles. En ciertos casos, tanto su ajuar como la importante presencia del banquete funerario, indican su alto estatus social.
\end{abstract}

Palabras Clave: II Edad del Hierro. Celtíberos, Vettones, Vacceos. Necrópolis. Enterramientos femeninos. Enterramientos infantiles. Ajuar. Banquete funerario. Género

\section{Summary}

In this paper we present an approach to the burial record in celtiberians, vaccaei and vettons necropoli during the 2 nd Iron Age in the Iberian península.We emphasize the female and child burials studies. In some cases, both the grave goods and the significant presence of the funeral feast, indicate their high social status.

Keywords: 2nd Iron Age.Celtiberians,vaccaei, vettons, female and infant burials. Grave goods. Funeral feast. Gender

Aunque sabemos que la representación del género en el registro funerario, no tiene por qué reflejar directamente las relaciones de género de la sociedad de los vivos, éste es un campo que permite informaciones muy interesantes (Arnold y Wicker, 2001; Arnold, 2006). En este artículo, que escribimos como homenaje al Profesor Bendala en esta nueva etapa de su vida, plantearemos una aproximación a estos estudios, durante la II Edad del Hierro en la Península Ibérica, centrada en los pueblos celtíberos, vettones y vacceos (Almagro-Gorbea et alii, 2001; Albero y Arnold, 2004; Jimeno, 2005; Álvarez-Sanchís, 2008; Burillo, 2010).

\section{EL MUNDO FUNERARIO CON PERSPECTIVA DE GÉNERO}

La mayoría de las aproximaciones teóricas, tanto procesuales como postprocesuales, coinciden al considerar que entre la esfera de los muertos y la de los vivos pueden establecerse patrones que sean significativos, a pesar de las diferencias con las que cada cultura se enfrenta al hecho común de la muerte. Al mismo tiempo, no debemos olvidar que los datos del registro funerario no pueden estudiarse de forma aislada, sino siempre en relación con los contextos del hábitat, los espacios sagrados, su territorio, etc. En definitiva, el mundo funerario forma parte del paisaje que da 
sentido y cohesión al grupo y ayuda a definir no solo sus límites geográficos, sino también los míticos (Hernando 2005).

M.L. Sørensen considera que en la representación de la muerte, se expresan diferentes formas de categorización social, entre las que se incluye el género. Es lo que ella denomina visualization and ideological reproduction of gender systems (Sørensen, 2000: 85). También es interesante señalar cómo en muchas culturas, las propias tumbas pueden llegar a reproducir las casas y su memoria - pensemos en el clásico ejemplo de las culturas villanoviana o etrusca-. En este sentido, tendríamos que mencionar también la existencia, a lo largo del tiempo, de enterramientos infantiles bajo las viviendas (Chapa, 2003; Torija et alii, 2010, Olmo Enciso, en prensa). La evocación del hogar puede establecerse, asimismo, a través de los objetos depositados como parte del ajuar funerario, y que pueden incluir desde objetos personales; amuletos protectores; instrumentos de trabajo; ollas de cocina, etc. Estos objetos son de suma importancia porque nos permiten aproximarnos a las identidades familiares (Gilchrist 2005; Delgado y Ferrer, 2012).

Desde los inicios de la investigación arqueológica, ésta ha mostrado interés en sexuar los restos funerarios excavados pero, en general, este interés se ha limitado a señalar, cuando era posible, el sexo y la edad de los individuos enterrados. Estas clasificaciones se han establecido, en muchas ocasiones, a partir de los restos osteológicos mientras que en otras, el sexo se ha adjudicado exclusivamente en función del análisis de los ajuares -varones, si aparecen armas; mujeres si hay presencia de elementos textiles-, o simplemente asumiendo que si el enterramiento destacaba por su riqueza y rango social, estaríamos ante la tumba de un varón. Sabemos que a través del registro funerario pueden establecerse diversas formas de construcción de la identidad y el género, que se manifiestan a partir del diseño del paisaje funerario; la distribución de los enterramientos en la necrópolis; la forma de deposición del cadáver; su tratamiento; la orientación del cuerpo o sus restos cremados; la distribución espacial de los objetos en las tumbas; el tipo, número y materiales de los ajuares; etc. (Arnold y Wicker, 2001; Arnold, 2006). Al mismo tiempo, hay que tener en cuenta que aunque se puedan sexuar los enterramientos, éstos no siempre tienen que mostrar diferencias, por ejemplo, en cuanto a su ajuar, orientación, ubicación en la necrópolis, presencia o ausencia de banquetes funerarios, etc. Por otra parte, en muchas ocasiones nos olvidamos que las diferencias que presentan los enterramientos, no las determina el género o la edad, sino la pertenencia a determinados segmentos sociales de la población. De igual modo, sabemos que los objetos no adquieren el mismo significado en todas las culturas. Por ejemplo, en los botones con perforación en V son característicos de los enterramientos masculinos o femeninos, dependiendo del área geográfica y cultural a la que pertenezcan (Gómez Vázquez, en prensa). Por otro lado, el valor del significado de un objeto, se halla determinado por la propia interpretación que demos al contexto arqueológico en el que se encuentra.

Por lo tanto, las relaciones entre ajuares, género y sexo, deben justificarse a través de la investigación arqueológica (Lucy 1997). Somos conscientes, sin embargo, que las armas o las joyas, por ejemplo, siguen siendo indicadores muy fiables en la adscripción del sexo biológico de los enterramientos, aunque tengamos excepciones tan llamativas como el famoso enterramiento de la Dama de Baza (Dommasnes, en 2012; Quesada 2010 y 2012; Prados, 2010 b y 2012; Chapa e Izquierdo, 2010). Por ello, no debemos olvidar que las excepciones también deben contemplarse y explicarse con metodología arqueológica, sin dejarnos llevar por prejuicios que, en muchos casos, tienen que ver con nuestra propia forma de entender el presente.

Asimismo, es un error considerar que solo pueden existir dos géneros, masculino y femenino, exclusivamente sobre la base de dos sexos, hombre y mujer. Existen estudios muy interesantes sobre otras construcciones de género en diferentes culturas, como los castrati; los Berdaches de Norte América; las Hijras de La India, etc. Contamos, incluso, con ejemplos contemporáneos muy ilustrativos, pero es un tema que excede estas páginas, lo mismo que ocurre con los planteamientos de la llamada Queer Archaeology (Dowson, 2000; Voss, 2008). Por otra parte, no debemos olvidar que, en numerosas ocasiones, nuestras investigaciones se centran en los enterramientos de un grupo muy reducido de la población, que suele coincidir con los grupos sociales dominantes, ya que los ritos funerarios seguidos por la gran mayoría de la población - en muchas 
ocasiones, sin derecho a enterrarse en estos espacios funerarios-, pueden no haber dejado huellas arqueológicas.

Otra cuestión que debemos tener presente, al enfrentarnos al estudio de una sociedad a partir de su registro funerario es que, a pesar de su obviedad, son los vivos los que entierran a los muertos. Por esta razón, los rituales funerarios- intencionadamente manipulados por los vivos-, están reflejando la idea que bien la familia o bien el grupo que realiza las exequias, desea que permanezca del difunto en la posteridad.

Asimismo, a partir del registro funerario pueden inferirse también diversas actividades de mantenimiento, reflejo de la importancia de estas labores vinculadas con el hogar y la producción doméstica. En este sentido, resulta muy interesante el destacado papel que tiene la mujer en muchas culturas en la preparación del cadáver para su entierro, (Gilchrist, 2005; Delgado y Ferrer 2007; y 2012). Del mismo modo, en muchas ocasiones, tanto a través de los ajuares y rituales funerarios como a partir de diferentes métodos de análisis -como los de isótopos-, puede establecerse la importancia de las alianzas matrimoniales entre poblaciones lejanas, aunque sea todavía un tema complejo y que, por supuesto, no afecta solo a las mujeres.

Existen diversas publicaciones que se han ocupado, en los últimos años, en analizar el registro funerario con perspectiva de género en la cultura ibérica (Izquierdo 2000; 2007; Rísquez y Hornos, 2005; Rísquez y García Luque 2007; García Luque, 2008; Prados 2010 b). Por ello, me ha parecido más interesante, en esta ocasión, centrarme en las culturas del interior peninsular, en concreto, en la celtibérica, vettona y vaccea.

Como es sabido, el rito de enterramiento característico de las culturas de la II Edad del Hierro de la Península Ibérica fue la cremación del cadáver. Sin embargo, en las culturas del noroeste y norte peninsular, aun hoy en día, desconocemos qué tipo de ritual funerario siguieron para acompañar a sus muertos, puesto que no ha sido posible identificar su huella en el registro arqueológico, hasta su contacto directo con el mundo romano. Entre otros posibles ritos, se ha propuesto la posible exposición de los cadáveres a los agentes naturales y animales carroñeros $\mathrm{u}$ otro tipo de costumbres rituales que implicaran arrojar los cuerpos o los restos de su cremación a las aguas (Ruiz Zapatero y Lorrio, 1995). También en el extremo occidental del territorio Vetton, en las actuales provincias de Zamora y Salamanca, la información sobre los sitios funerarios es casi nula debido, posiblemente, al parentesco cultural de estos territorios con otros sectores de la fachada atlántica (Berrocal-Rangel, 2001). Por su parte, las necrópolis de cremación de los pueblos del centro de la P. Ibérica : Celtíberos; Vettones excepto la zona Occidental - y Vacceos, lo mismo que las de los pueblos Ibéricos -con excepción de los Turdetanos-, han sido una de las señas de identidad características, desde los inicios de la investigación arqueológica sobre estas culturas (Álvarez- Sanchís, 2008; Burillo, 1990; Baquedano, 2001; Lorrio, 2001; Cerdeño y García Huerta, 2005; Martínez et alii, 2005; Jimeno, 2005).

\section{EL RITUAL FUNERARIO ENTRE LOS Celtíberos, Vettones y Vacceos}

Entre estos pueblos existen variantes de origen étnico, social y cronológico, aunque el ritual más común suele ser una simple urna funeraria depositada en un hoyo. Como ya hemos comentado, el conocimiento arqueológico de estas culturas se basó, durante muchos años, casi exclusivamente en la información proporcionada por sus característicos lugares de enterramiento. Entre ellos, destacan las dos grandes necrópolis de la provincia de Ávila, excavadas en los años treinta del siglo pasado: Las Cogotas y La Osera. La primera, con 1613 tumbas distribuidas en cuatro zonas, es la única que ha sido publicada, prácticamente en su totalidad y a partir de la cual Martín Valls (1999), estableció la existencia de cuatro grupos sociales, a los que nos referiremos más adelante. Por su parte, La Osera -necrópolis del Castro de La Mesa de Miranda-, presenta unas 2230 sepulturas distribuídas en seis zonas que está siendo objeto de revisión por parte de I. Baquedano (2001; 2010). Del mismo modo, ha proporcionado datos interesantes el análisis de la necrópolis de la Mercadera (Soria), publicada en los años treinta (Lorrio, 1990).

Las necrópolis podían situarse a una pequeña distancia de las puertas de los poblados, o en las próximidades de ríos y arroyos debido no sólo a la importancia real que el agua tenía para estos pueblos, sino también a su carácter simbólico (Álvarez Sanchis, 1999). 
El ritual funerario generalizado, como sabemos, era la cremación que consistía en quemar el cadáver en una pira funeraria-ustrinum-, tras lo cual habría una recogida selectiva de los huesos calcinados y el posterior traslado de los restos óseos, en unión- cuando los había- de ajuares personales y ofrendas al espacio sacro cementerial. En Las Cogotas, en el espacio situado entre la necrópolis y el castro, aparecieron cenizas y restos calcinados de huesos y pequeñas escorias de metal, evidencias que podrían interpretarse a favor de la existencia de lugares específicos reservados para la cremación de los cadáveres (Martín Valls, 1986-87; Kurtz, 1987; ÁlvarezSanchís et alii, 1998; Álvarez-Sanchís, 2001 y 2008). Los datos que nos proporcionan las necrópolis en las que se han podido analizar un número significativo de restos osteológicos, parecen confirmar una recogida muy selectiva de los huesos, principalmente los restos de huesos largos y las partes del cráneo. Este es el caso de la necrópolis de Numancia, donde la media de los restos humanos de cada tumba se reducía a 5,73 gramos (Jimeno et aii,. 1996; Martínez et alii, 2005). Los huesos y las cenizas resultantes de la cremación, podían seguir diferentes opciones. Desde su selección y deposición en hoyos sin urna -seguramente se recogerían en algún tipo de envoltorio orgánico que no ha dejado huella-, o también mediante su introducción en simples urnas, sin ajuar. En realidad, este último tipo representaba a la mayoría de la población. Son las llamadas "tumbas pobres". Los enterramientos aparecen señalados de distintos modos. Podemos citar desde las sepulturas sencillas, sin demarcación externa, en las que solo se colocaba un plato o una laja de piedra encima de la urna cerámica, a otros casos en los que los hoyos se acompañan de lajas de caliza que protegían y destacaban el enterramiento, como en la necrópolis de El Raso; o en El Romazal (Fernández Gómez, 1997; Hernández, 1998; Hernández et alii, 2008). En otros casos, encontramos tumbas más complejas, que se señalizaban mediante una estela de piedra de tamaño variable, en torno a un metro de altura, como en Las Cogotas. En ocasiones, se incorporan estructuras tumulares y encanchados de piedra, como se observa en La Osera; El Mercadillo; La Coraja; Alcántara; La Yunta; o Sigüenza, entre otras (Lorrio, 2001;
Alvarez Sanchis, 2004 y 2008; Cerdeño, 2010; Baquedano y Martín, 2010; Cerdeño, 2010). La presencia de estructuras sobre las tumbas ha sido objeto de atención por parte de muchos autores, que han debatido en torno a si debía relacionarse su posible origen en la P. Ibérica con el bagaje de los Campos de Urnas o si, por el contrario, se trataría del resultado de una evolución interna a partir de la tradición megalítica peninsular. Lo que parece claro es que el espacio funerario de estos pueblos, estaba perfectamente diseñado y organizado. Ya el Marqués de Cerralbo aseguró que las tumbas de Aguilar de Anguita o Luzaga (Guadalajara), estaban señalizadas por estelas que se alineaban formando calles paralelas. En ocasiones, esta distribución se ha interpretado en relación con determinados conocimientos astronómicos y fechas de calendario, vinculados con los ciclos climáticos, tan importantes para las actividades agrícolas y posiblemente rituales (Baquedano y Escorza, 2008; Jimeno et alii, 2010). De igual modo, se caracterizan por una particular distribución del espacio funerario, que consiste en concentrar los enterramientos en varios sectores separados, a su vez, por espacios estériles. Cuestión muy debatida es la lectura sociológica que se infiere de este último aspecto. Álvarez Sanchís (1999; 2004), defiende que las áreas funerarias excluyentes pueden reflejar un sistema de descendencia líneal en los grupos familiares cuya economía se basaba en el control de diferentes medios de producción, y que se enterraban separadamente para reforzar simbólicamente sus derechos. Por tanto, según este autor, es muy posible que las distintas zonas en las que se dividían las necrópolis correspondiesen, a su vez, a cada una de las gentilidades o linajes que habitaban el castro.

También se ha propuesto una clara jerarquización social en función de la riqueza de los ajuares depositados en determinados enterramientos, que nos indica que existieron marcadas diferencias sociales entre los miembros de cada comunidad. En general, podemos hablar de una estructura piramidal, con una élite en la cúspide que posee caballos y armas de lujo significativos de su posición, frente a un grupo de guerreros más amplio con una panoplia más modesta. Por debajo de este grupo se hallaría el estamento de artesanos y comerciantes. Y por último, casi el 
$85 \%$, los enterramientos sin ajuar, que corresponderían a los individuos más humildes, tal vez siervos y esclavos. De hecho, Martín Valls (1999), a partir del minucioso estudio de la necrópolis de Las Cogotas, establece cuatro grupos sociales. En el primero sitúa a los guerreros con ajuares suntuarios, entre los que destacan las armas y arreos de caballo, que suponen más del $18 \%$ de las tumbas con ajuar, y un $2,8 \%$ del total de enterramientos, con varios niveles de riqueza. En el segundo grupo incluiría a los artesanos, cuyos ajuares contienen punzones y algunas herramientas y que representan, aproximadamente, el 5\% de los enterramientos con ajuar y el $0,7 \%$ del total. En un tercer grupo incluye a las mujeres, que identifica por su asociación con fusayolas y pequeños elementos de adorno, como brazaletes, anillos o fíbulas, y que supone el $19,5 \%$ de las tumbas con ajuar y el $3 \%$ del total. Por último, el cuarto grupo -otros- lo constituyen aquellos enterramientos que contienen vasos cerámicos y algunos elementos de adorno, y que representan el $57,5 \%$ de las tumbas con ajuar y el $8,8 \%$ del total. Si tenemos en cuenta sólo las tumbas con ajuar, la composición resulta bastante similar en el cementerio de La Osera. Sobre esta última necrópolis - que estuvo en uso aproximadamente entre los s. IV y III a C., I.Baquedano ha publicado diferentes estudios en los últimos años $(1996 ; 2001 ; 2010)$. Esta investigadora corrobora la pirámide social con los cuatro grupos característicos que acabamos de ver: una élite militar a la cabeza y un grupo de guerreros más modestos, por debajo de ellos los artesanos, comerciantes y mujeres y, finalmente, los enterramientos sin ajuares que corresponderían a la gente más humilde. Los ajuares, como hemos indicado, reflejan una jerarquización social y varía desde una urna y una panoplia completa de guerrero en las tumbas más ricas, con espada, dos lanzas, escudo y casco en contadas ocasiones, a tumbas pobres, sin armas o con solo una lanza.

$\mathrm{El}$ auge de las necrópolis se produce hacia el s. IV a.C., cuando se generalizan las tumbas ricas que evidencian una sociedad regida por las élites guerreras con frecuentes atalajes de caballo que constatan la formación de una clase aristocrática ecuestre. Además de las armas, -en general ritualmente inutilizadas-, y los arreos de caballo, entre los ajuares encontramos también objetos de ador- no personal como fíbulas, broches de cinturón, pectorales, collares, canicas, fusayolas, agujas, etc. (Burillo, 1990; Álvarez Sanchís, 2001; Lorrio, 2001; Álvarez Sanchis et alii, 2001; Lorrio, 2001; Baquedano, 2001; Cerdeño, 2010; Baquedano y Martín, 2010). (fig 1)

Como vemos por estas clasificaciones, las mujeres se incluyen, en su conjunto, en un único grupo social, sin tener en cuenta las diferencias entre los diversos tipos de enterramientos femeninos, en función de sus características, emplazamiento, diversidad de ajuar, etc.

La creencia en la inmortalidad llevó a estos pueblos a trasladar al ámbito de ultratumba, formando parte de su ajuar, aquellos elementos que durante la vida habían simbolizado su estatus, ya sea por sexo, edad o condición social, así como a incluir frecuentemente alimentos (Sagardoy y Chorda, 2010; Sanz, Romero y Gorri, 2010). Aunque este último aspecto ha sido relegado en muchos estudios, su importancia resulta manifiesta. De hecho, P. Brun (2009) incluye, entre los rasgos que caracteriza como inherentes a la conducta aristocrática de los varones guerreros, -junto al armamento, la conducción del caballo, y los objetos de adorno personal-, el banquete . Las necrópolis, como en tantas culturas, cumplieron la doble finalidad de acogimiento definitivo para el muerto, pero también de lugar de culto para los vivos. De esta forma, en algunos casos encontramos una serie de recipientes que acompañaban al difunto y que posiblemente formaron parte del ritual del banquete funerario y que contendrían restos de comida, leche, vino y cerveza. Entre la comida consumida durante estos actos fúnebres, destaca la carne. Podemos citar la presencia de carne de vaca, oveja y ciervo en las necrópolis de Sigüenza, Molina, La Yunta y Aragoncilo (Cerdeño y García Huerta, 2005; Cerdeño, 2010); en Herrería, por su parte, se constata también la existencia de aves (Sagardoy y Chorda, 2010) y en Pintia de cordero, conejo y cerdo (Sanz Mínguez, 1997; Sanz Mínguez et alii, 2003: 155; Sanz Mínguez y Romero Carnicero, 2010: 406). También los análisis paleoantropológicos realizados en Numancia nos indican la existencia de diferentes patrones alimenticios (Jimeno et alii, 1996). 


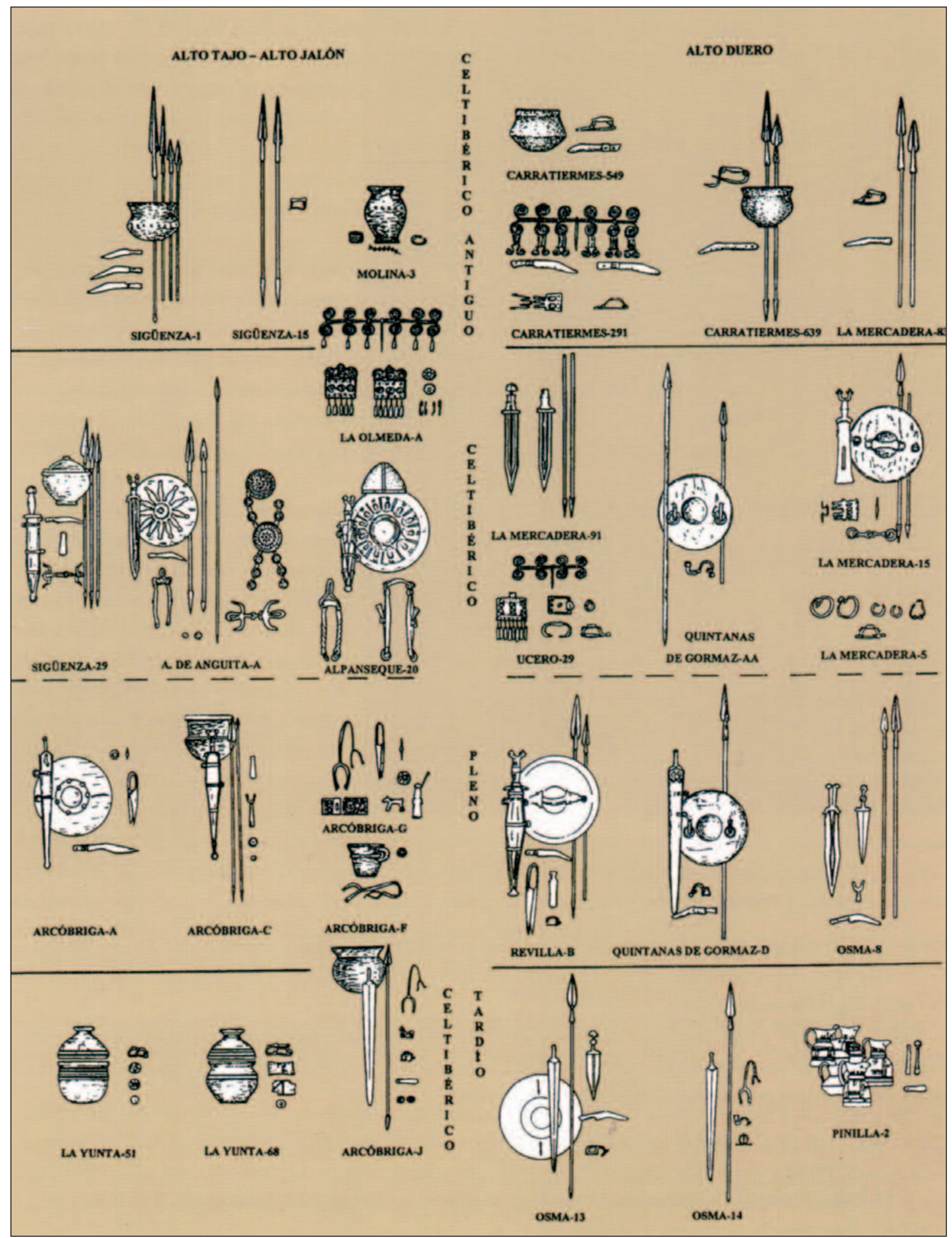

Figura 1. Cuadro evolutivo de los ajuares funerarios celtibéricos (según Lorrio 2001, pág 190) 
El consumo de carnes durante el banquete funerario, debíó implicar un importante reconocimiento social. Nos interesa destacar, como veremos por los datos aportados por excavaciones recientes, que no encontramos sólo indicios de banquetes funerarios vinculados con las tumbas de varones, sino también en tumbas destacadas por su rico ajuar, tanto femeninas como infantiles (Sanz Minguez; Romero Carnicero y Górriz Gañán, 2010). En cuanto a la bebida, además de la leche, podemos citar el consumo de cerveza y el vino. En relación con el consumo de esta última bebida, son muy interesantes los trabajos que vienen desarrollándose en los últimos años, tanto en necrópolis como en ambientes domésticos (Burillo, 2010; Sanz, Romero y Gorriz, 2010). En concreto, destaca el caso de la necrópolis de Las Ruedas de Pintia, donde se demuestra que, al igual que ocurre con las carnes, el consumo de vino se realizaba también en los enterramientos de mujeres y niños de alto estatus (Sanz Mínguez; Romero Carnicero y Górriz Gañán , 2010). Es importante resaltar cómo las investigaciones arqueológicas en torno a la comensalidad en diferentes épocas, están aportando datos muy interesantes, como se recoge en la reciente publicación coordinada por Aranda; Montón y Sánchez Romero (2011).

Por otra parte, es muy posible, -aunque difícil de comprobar- como sabemos por otras culturas, que fueran las mujeres las encargadas de la preparación de los alimentos durante estas ceremonias (Gilchrist, 2005; Delgado y Ferrer, 2007; Delgado y Ferrer). De hecho, entre los recipientes depositados en los enterramientos, podemos encontrar una tipología cerámica completa de la vajilla de cocina.

Un segundo tipo de ritual mencionado por las fuentes clasícas, y corroborado por la iconografía de la cerámica numantina, era el rito reservado por su gran honor-, a los guerreros muertos en combate. El cadáver se dejaba expuesto para su descarnación por parte de los buitres (Sopeña, 2010 ) (fig 2 ). También se han localizado cenotafios que no contenían restos óseos humanos, y

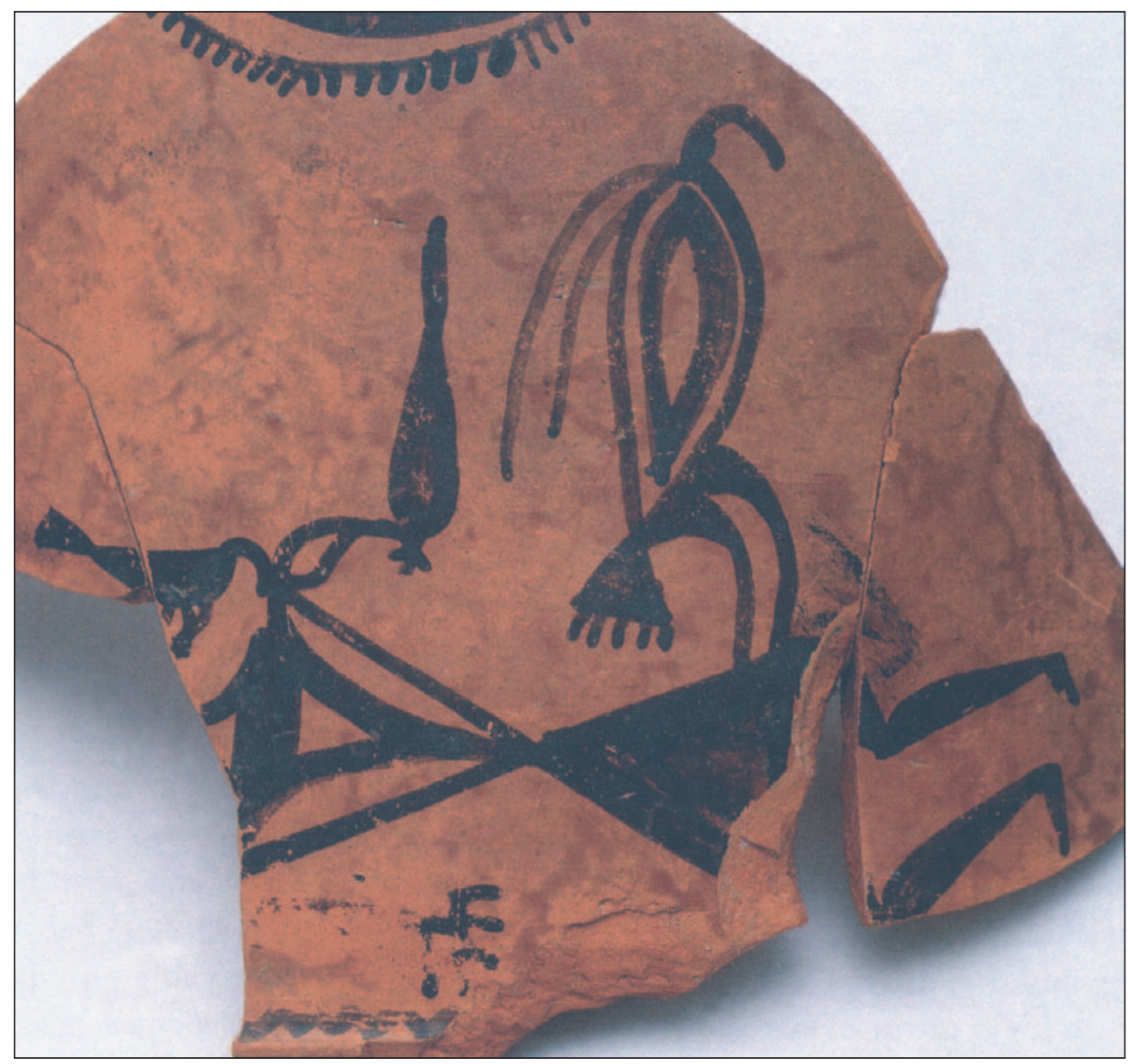

Figura 2. Fragmento de cerámica con representación de un buitre de Numancia (Museo de Numancia) 
que se interpretan como las tumbas de individuos cuyos cadáveres no pudieron ser recuperados. De hecho, en la necrópolis de Numancia, el $31 \%$ de las tumbas contienen exclusivamente restos de fauna, que han sido interpretados como "enterramientos simbólicos, condicionados por la dificultad de recuperar los cadáveres" (Jimeno et alii, 1996: 37). Es muy probable, por tanto, que estos cenotafios estuvieran honrando a individuos masculinos, seguramente pertenecientes al estamento de los guerreros.

Por su parte los niños de corta edad, neonatos, y fetos, se inhumaban en los espacios domésticos, en general bajo el suelo de las casas; ritual, que como sabemos, se constata también en el ámbito de los pueblos ibéricos. Sin embargo, tenemos también ejemplos de enterramientos infantiles, en general dobles, incluidos en las necrópolis, con ricos ajuares y con restos de banquetes funerario (Torija et alii, 2010; Sanz Mínguez y Romero Carnicero, 2010).

\section{LA PRESENCIA DE ENTERRAMIENTOS FEME- NINOS}

Solo a partir de la década de 1980 , con los nuevos planteamientos teóricos que llegan a la investigación española, se empiezan a superar los estudios centrados en los análisis de los ajuares y la tipología de las urnas, y comienzan a plantearse cuestiones relacionadas con las estructuras sociales, la edad y los propios ritos funerarios. Sin embargo, aún hoy en día, la información disponible sobre los diferentes segmentos sociales de estas poblaciones es muy escasa y en muchas ocasiones, como hemos visto, se incluye al grupo de mujeres, como si se tratara de un grupo social uniforme. La fascinación que sintieron los primeros excavadores por las armas de los ajuares, hizo que todo su interés se centrara en los guerreros e impidió siquiera visibilizar a otros grupos de población y entre estos últimos, destaca la ausencia reiterada de información relativa a los posibles enterramientos femeninos. Es cierto que en algunas ocasiones, se plantea que la falta de armas y la presencia de determinados objetos como broches de cinturón, collares, fíbulas, y fusayolas, agujas de coser, etc., pudieran ser indicativas de la presencia de tumbas de mujeres. Este sería el caso de las necrópolis de Las Cogotas o La Osera, donde uno de estos grupos- como ya hemos señalado- lo formarían las tumbas sin armas, pero con alguna pieza de otro tipo. Sus ajuares varían desde un recipiente cerámico hasta pequeñas piezas de adorno, generalmente de bronce, relacionadas con la indumentaria -fíbulas, brazaletes, cuentas de collar, etc.-, o con actividades vinculadas al mundo del tejido, como las fusayolas o agujas. Desgraciadamente, a partir de los datos aportados por las antiguas excavaciones, no se pueden realizar análisis que confirmen o refuten algunas de estas hipótesis pero, en general, diversos investigadores, entre otros Martin Valls (1999); Baquedano ( 2001); y Álvarez Sanchis (2004), consideran este grupo de enterramientos como femenino, debido a la relación de su proximidad con el segmento "más rico" dentro de los grupos que poseen armamento. Sin embargo, la práctica ausencia de estudios paleoantropológicos, como acabamos de comentar, ha dificultado la aproximación al estudio del mundo funerario de estos pueblos peninsulares, a partir del género; grupos de edad; etc. ya que la información que tenemos sobre la presencia de enterramientos femeninos se reduce a muy pocas necrópolis. En algunos casos, son las tumbas dobles las que nos han aportado datos interesantes. Los casos más frecuentes son las tumbas de adulto e infantil interpretadas, en general, como madre e hijo, o bien la de dos adultos, varón y mujer, unidos seguramente por vínculos familiares, aunque sin pruebas de ADN que lo confirmen. Una de las necrópolis que ofrece datos interesantes es Carratiermes (Tiermes, Soria) - que estuvo en uso desde el s. VI hasta su abandono en el s. I d.C- donde se han excavado 644 tumbas, que han arrojado una importantísima documentación sobre diferentes aspectos de la cultura material: tipología cerámica, armamento, adornos, etc. (Argente et alii, 2001). Los estudios antropológicos realizados han revelado un equilibrio entre la ratio de varones y mujeres, así como la existencia de 28 tumbas con dobles cremaciones de mujeres y niños o de dos adultos, varón y mujer. La media de edad se situaba entre los 3035 años, aunque hay individuos que alcanzaron los 60 ó 70 años de edad (Argente et alii, 2001). También resultan interesantes los datos sobre algunos conjuntos dobles como las tumbas $30 \mathrm{y}$ 50 de la necrópolis vaccea de Las Ruedas, Pintia (Padilla de Duero, Valladolid). Nos referimos a enterramientios sincrónicos que han sido objeto de depósito en un loculus único o común y que, por tanto, cabe suponer que mantuvieran en vida, algún tipo de vínculo muy estrecho. Así, en la sepultura 30 una pequeña laja caliza servía de 
separación a dos urnas cinerarias y sus ajuares y ofrendas correspondientes. Los análisis antropológicos han concluído que se trataba de un varón de 40-50 años y de una mujer de 18-20 años. Los diecisiete objetos que incluye el primero, frente a los siete de la segunda han permitido, a sus excavadores interpretarla como la tumba de un guerrero de estatus elevado y una mujer estrechamente vinculada a él (Sanz Mínguez y Martín Valls, 2001). Las últimas investigaciones en esta necrópolis vaccea de Pintia, con cuatro nuevas tumbas femeninas (Sanz Mínguez y Romero Carnicero, 2010) , están aportando datos muy interesantes que abren nuevas perspectivas en el conocimiento de la estructura social de estas poblaciones. Se trata de las tumbas de tres mujeres y una niña, que nos indican la existencia de enterramientos femeninos de alto estatus, posiblemente vinculados a las élites guerreras. Se fechan en torno al s.II a C. La Tumba 122 se identifica con una mujer joven. Entre los objetos que formaban parte de su ajuar, destaca un extraordinario broche de cinturón de bronce, que ratifica su alto estatus social, así como la presencia de varios contenedores de ungüentos a base de aceite de oliva perfumado. Asimismo, como parte del ritual funerario, se debió incluir un banquete funerario, en el que se utilizaron diferentes recipientes como una olla con restos de cordero o la crátera para el vino (Sanz Mínguez y Romero Carnicero, 2010, 404-406).

Otro caso, que podemos destacar, es la llamada Tumba $127 a$ y $b$. Se trata de un conjunto doble y sincrónico, con la asociación de dos individuos dentro del mismo loculus. Sus excavadores consideran que nos hallamos ante relaciones de parentesco. Se trata de una mujer adulta y una niña de unos 8 años, tal vez madre e hija. La tumba infantil es la más rica, lo que, según sus excavadores, demuestra que la riqueza y el estatus social se adquirían entre los vacceos, a partir del nacimiento, incluidas las mujeres. La riqueza de estos conjuntos queda en evidencia por el importante número de objetos: 21 la mujer adulta y 67 la niña, así como por las numerosas ofrendas de animales. El conjunto $127 a$, (fig 3) que corresponde a la mujer adulta, contiene, entre otros objetos, dos ollas, una de ellas utilizada como urna funeraria, una cajita zoomorfa, cuatro canicas y una fusayola. Destacan, asimis-

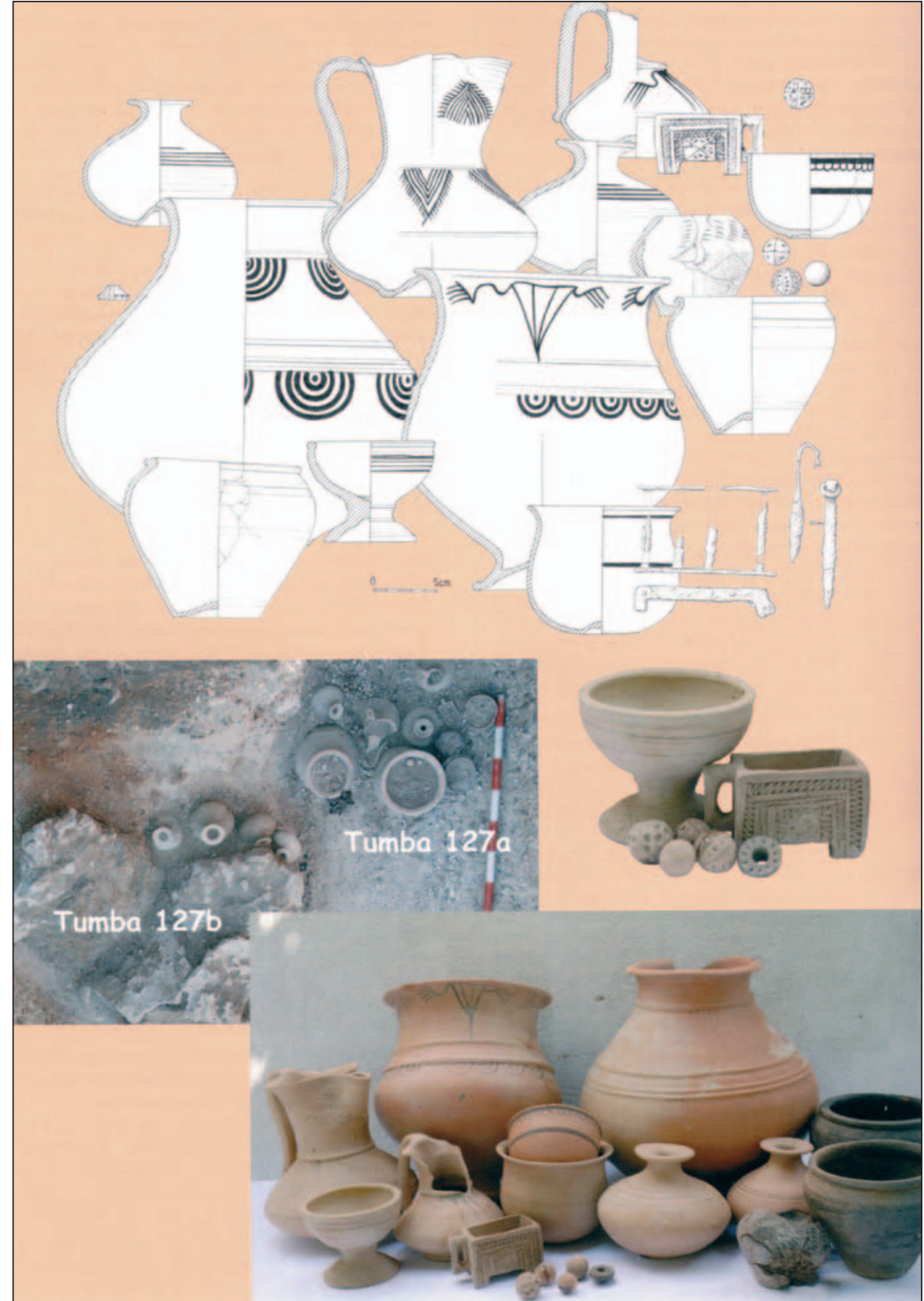

Figura 3. Conjunto funerario 127a Pintia (según Sanz Minguez y Romero Carnicero, 2010) 
mo, elementos para fuego miniaturizados de hierro: una parrilla y dos pinzas que, junto con los restos de cordero y cerdo, testimoniarían, asimismo, la existencia del banquete funerario (Sanz Mínguez y Romero Carnicero, 2010, 406407). El conjunto $127 b$ (fig 4), por su parte, coincide con el enterramiento infantil que, como ya hemos comentado, muestra una mayor riqueza y variedad de objetos, entre los que destacan diferentes recipientes de cerámica; objetos de pasta vítrea; ámbar; piedra caliza; hierro, bronce e incluso un huevo pintado. Además de un conjunto de 6 fíbulas, 19 cánicas, una cajita y un sonajero, adornos de cerámica para el cabello, etc . También están presentes objetos miniaturizados de hierro, de nuevo una parrilla y unas pinzas para el fuego que, en palabras de sus excavadores, constituyen una referencia simbólica al banquete funerario (Sanz Mínguez y Romero Carnicero, 2010: 407).

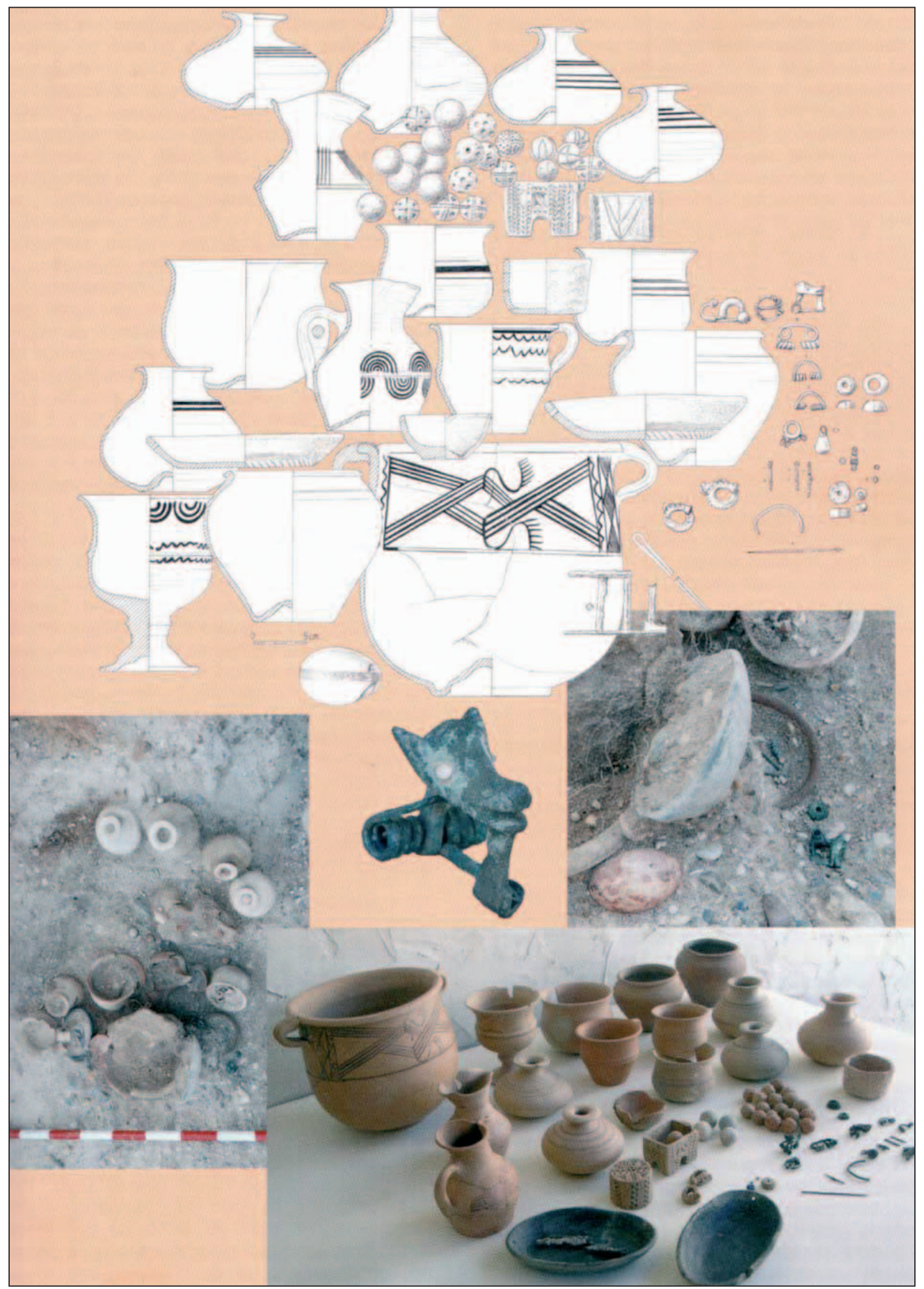

Figura 4. Conjunto funerario 127b Pintia (según Sanz Minguez y Romero Carnicero, 2010) 
$\mathrm{Si}$, en efecto, se trata de un enterramiento de una madre con su hija, no deja de sorprendernos que el individuo infantil tuviera un mayor estatus que la madre, como pone en evidencia su destacadísimo ajuar.

Por último, queremos referirnos a la Tumba 128 de esta misma necrópolis (Sanz Mínguez y Romero Carnicero, 2010: 407-410). Se trata del enterramiento de una mujer adulta, cuyo ajuar estaba compuesto por un importante conjunto cerámico: una cajita zoomorfa, un cuchillo de hierro, una aguja de coser de bronce y dos cuentas de collar de pasta vítrea y abundantísimos restos faunísticos, con presencia mayoritaria de cordero, conejo y también cerdo que, una vez más, ponen de manifiesto la importancia que se dio al banquete funerario en estos enterramientos. Por ello, queda patente, que el banquete formaba parte también de los rituales funerarios de las mujeres de alto estatus y no sólo de los varones (Arnold 1996).

Un tema recurrente en la investigación es el que plantea la importancia del establecimiento y mantenimiento de las relaciones intercomunitarias a través del matrimonio fuera del grupo de filiación. La consecuencia habitual sería que las mujeres viajarían de su grupo endógeno al ajeno, para reforzar las alianzas entre dos grupos, como ya señaló para estos mismos pueblos, hace algunos años, Sánchez Moreno (1997). Sin embargo, resulta compleja la constatación arqueológica de este hecho, aunque se ha sugerido que algunos broches de cinturón de Pintia podrían corresponder a "princesas turmogas" desposadas con "príncipes vacceos (Sanz Minguez y Romero Carnicero, 2010). El tema de los matrimonios exógenos se está estudiando con detenimiento en otras culturas, como en la Cultura Campaniforme, o en la E. del Hierro escandinavo, en las que los análisis de isótopos (relacionados con la alimentación, consumos de agua, etc) están aportando resultados muy interesantes (Dommasnes 2012), pero exceden el espacio de este artículo.

\section{REFLEXIONES FINALES}

Está claro, que en el momento actual de nuestras investigaciones, se hace indispensable contar con análisis osteológicos fíables que permitan identificar por sí mismos- y no en función de su ajuar-, el sexo y la edad de los individuos depositados en las necrópolis. Es posible que, al igual que ocurre en algunas tumbas de la cultura ibéri$\mathrm{ca}$, en ciertos enterramientos, la presencia de armas y atalajes puedan ser indicativos de su adscripción a grupos sociales, por lo que determinadas mujeres e individuos infantiles, podrían también enterrarse con los objetos que son propios de su rango. Esto nos lleva, asimismo, a rechazar la consideración de las mujeres como un grupo social, desmentido por los resultados de las excavaciones en diversas necrópolis, entre la que podemos destacar Las Ruedas, en Pintia (Valladolid). No negamos, sin embargo, la necesidad de definir los ajuares en función de grupos de género y edad, pero siempre apoyados en los análisis paleoantropológicos. Otro aspecto destacable es la importancia que tuvieron los banquetes funerarios entre estas poblaciones, tanto en varones como en mujeres e infantiles de alto estatus. Es muy posible, además, que éstas últimas jugaran un papel destacable en los rituales funerarios, tanto en la preparación del cadáver, como en la elaboración del propio banquete funerario, si seguimos el ejemplo de otras muchas culturas.

\section{Bibliografía}

Almagro-Gorbea, M; Mariné, M y J. Álvarez-Sanchís (eds) (2001): Celtas y Vettones. Ávila

M. Alberro y B. Arnold (Eds) (2004): The Celts in the Iberian Peninsula, e-Keltoi. Journal of Interdisciplinary Celtic Studies. volume 6

Álvarez-Sanchís, J. (1999): Los Vettones. Bibliotheca Archaeologica Hispana 1, Madrid, Real Academia de la Historia.

Álvarez-Sanchís, J. (2001): "Los Vettones", en M. Almagro-Gorbea; M. Mariné y Álvarez-Sanchís (Eds): Celtas y Vettones. Catálogo de la Exposición. Ávila

Álvarez Sanchís, J. (2004): "Oppida and Celtic society in western Spain”, M. Alberro y B. Arnold (eds): The Celts in the Iberian Peninsula, e-Keltoi. Journal of Interdisciplinary Celtic Studies. volume 6. 255-286

Álvarez Sanchís, J. (2008) (Ed): Arqueología Vettona. La Meseta Occidental en la Edad del Hierro. Zona Arqueológica, $\mathrm{n}^{\mathrm{o}} 12$

Álvarez Sanchís, J. (2008): "El descubrimiento de los Vettones. Las Cogotas y la cultura de los verracos", en J. Álvarez Sanchís, (2008) (Ed): Arqueología Vettona. La Meseta Occidental en la Edad del Hierro. Zona Arqueológica, $n^{\circ}$ 12: 14-43 
Aranda Jiménez, G; Montón-Subías, S y Sánchez Romero, M . (2011): Guess who's coming to Dinner. Feasting rituals in the Prehistoric Societies of Europe and the Near East. Oxbow books.

Arenas, J.A. (1999): La Edad del Hierro en el Sistema Ibérico Central, España. Oxford: BAR International Series 780

Argente, J.L., Díaz Díaz, A. y Bescós Corral, A. ( 2000): Tiermes V. Carratiermes, necrópolis celtibérica: campañas 1977 y 1986-1991. Arqueología en Castilla y León. Memorias 9. Valladolid: Junta de Castilla y León.

Arnold, B. (1996): "Cups of bronze and gold: Drinking equipment and status in Early Iron Age", en A. Meyer, P.C. Dawson, and D.T. Hanna (eds.), Debating complexity. Proceedings of the 26th Annual Chacmool Conference, Calgary pp. 104-112.

Arnold, B. (2006): "Gender and archaeological mortuary analysis", en Nelson, S. M. (ed.), Handbook of Gender in Archaeology, AltaMira Press: 137-170.

Arnold, B. y Wicker, N. L. (eds.) (2001): Gender and the Archaeology of Death, Oxford.

Baquedano, I. ( 2001): "La necrópolis de La Osera” , en M. Almagro Gorbea, M. Mariné, y J. ÁlvarezSanchís (eds) Celtas y Vettones. Ávila: Diputación Provincial de Ávila: 305-313.

Baquedano , I y Escorza, C.M. (1996): "Distribución espacial de una necrópolis de la II Edad del Hierro. La zona I de La Osera en Chamartín de la Sierra, Ávila”, Complutum, 7: 175-194

Baquedano , I y Escorza, C.M. (1996): "Sacerdotes y Vettones: el sol y las estrellas. Un mapa estelar en las necrópolis de La Osera”, en J. Álvarez Sanchís, J. (2008) (Ed): Arqueología Vettona. La Meseta Occidental en la Edad del Hierro. Zona Arqueológica, $\mathrm{n}^{\circ}$ 12: 310-321

Baquedano , I y Martín, C (2010): "Rito y estructura social en la necrópolis de La Osera (Chamartín, Ávila)", en F. Burillo (ed). Ritos y Mitos. VI Simposio sobre Celtíberos:421-432

Berrocal-Rangel, L (2001): “ Los pueblos célticos del Suroeste peninsular.” En M. Almagro-Gorbea, M Mariné, y J. Álvares-Sanchís (eds), Celtas y Vettones. Ávila: pp. 326-333. Ávila

Burillo, F. (Ed) (1990): Necrópolis celtibéricas. II Symposio sobre los celtíberos. Zaragoza

Burillo, F. (1998): Los Celtíberos: Etnias y Estados. Barcelona: Crítica
Burillo, F.(2010): "Vino y ritual en la Celtiberia", en F. Burillo (ed). Ritos y Mitos. VI Simposio sobre Celtíberos: 573-594

Brun, P (2009): "Vino, banquete y poder en la Europa centro-occidental (siglos VI-V a C)" en C. Sanz Mínguez and F. Romero Carnicero (Eds) El vino y el banquete en la Europa prerromana. Valladolid: 6780

Cabré, J. (1932): Excavaciones de Las Cogotas, Cardeñosa (Ávila). II. La necrópoli. Madrid. Junta Superior de Excavaciones y Antigüedades, 120.

Cerdeño, M.L. (2010): "Veinte años después: el ritual funerario de los celtíberos del Alto-Tajo , AltoJalón”, en F. Burillo (ed). Ritos y Mitos. VI Simposio sobre Celtíberos: $315-330$

Cerdeño, M.L. y García Huerta, R. ( 2005): "Las necrópolis celtibéricas del Alto-Tajo y Alto-Jalón", en Celtíberos. Tras la estela de Numancia. Soria: 239244

Chapa Brunet, T. (2003): "La percepción de la infancia en el mundo ibérico", en Trabajos de Prehistoria n ${ }^{\circ}$ 60, 1: $115-138$

Chapa Brunet, T. e Izquierdo, I. (2010): La Dama de Baza. Un viaje femenino al Más Allá, Ministerio de Cultura, Madrid.

Delgado, A. y Ferrer, M. (2007): “Alimentos para los muertos: mujeres, rituales funerarios e identidades coloniales", en P. González Marcén, P. et alii (eds.), Interpreting household practices: reflections on the social and cultural roles of maintenance activities, Treballs d'Arqueología, 13: 29-68

Delgado, A. y Ferrer, M (2012): "La muerte visita la casa: mujeres, cuidados y memorias familiares en los rituales funerarios fenicio-púnicos", en L. Prados (Ed) Arqueología Funeraria desde una perspectiva de género. II Jornadas Internacionales en la UAM. Madrid, 123-156

Díaz Díaz, A. y Argente Oliver, J.L. (1990): “La necrópolis de Carratiermes" en F. Burillo (ed) Necrópolis celtibéricas. II Symposio sobre los celtíberos. Zaragoza: 51-58

Dommasnes, L.H (2012): "Gender and funerary practices during the Scandinavian Iron Ages", en L. Prados (Ed) Arqueología Funeraria desde una perspectiva de género. II Jornadas Internacionales en la UAM. Madrid, 365-384

Dowson, T. A. (2000): "Why queer archaeology? An Introduction", World Archaeology, vol. 32, $\mathrm{n}^{\circ}$ 2: 161-16 
Fernández Gómez, F. (1997): La Necrópolis de la Edad del Hierro de "El Raso" (Candeleda, Ávila). "Las Guijas, B”. Valladolid. Junta de Castilla y León

Ferrer Martín, M (2012): Acrópolis sicilianas: Rituales, comunidades y poderes (ssX-VaC) Tesis Doctoral UPF en red.

García Huerta, R. y Antona, V ( 1992): La necrópolis celtibérica de La Yunta (Guadalajara): Campañas de 1984-1987 . Villarrobledo (Albacete), en R. de Balbín, J. Valiente y M.T. Mussat (eds) Arqueología en Guadalajara. Toledo: Junta de Comunidades de Castilla-La Mancha. 55-70.

García Huerta, R y Cerdeño, M.L. (2004): "Las necrópolis celtibéricas y la obra de Juan Cabré", en J. Blánquez y B. Rodríguez (eds), El arqueólogo Juan Cabré (1882-1947): la fotografía como técnica documental: $235-250$

Gilchrist, R .( 2005): “Cuidando a los muertos: las mujeres medievales en las pompas fúnebres" en González Marcén, P. - Montón, S. - Picazo, M. (eds), Dones i activitats de manteniment en temps de canvi. Treballs d'Arqueologia 11. 51-72. Universitat Autònoma de Barcelona, Bellaterra.

Gómez Vázquez, Emma: Aspectos sociales del Horizonte campaniforme en el interior peninsular (UAM).

Hernández Hernández, F (1998): “La necrópolis de El Romazal. Plasenzuela (Cáceres)”, J. Mangas y J. Alvar (Coord), Homenaje a J.M. Blázquez. Vol 2: $257-270$

Hernández, F; Galán, E y Martín Bravo, A (2008): “La necrópolis prerromana de El Romazal I (Plasenzuela, Cáceres)", en J. Álvarez-Sanchís, (2008) (Ed): Arqueología Vettona. La Meseta Occidental en la Edad del Hierro. Zona Arqueológica, $n^{\circ}$ 12: 322-337

Hernando, (2005): "Por qué la Historia no ha valorado las actividades de mantenimiento?", Treballs dÁrqueologia 11: 115-133

Izquierdo Peraile, I (2000): Monumentos funerarios ibéricos: los pilares-estela, Valencia.

Jimeno, A (Ed) (2005): Celtíberos. Tras la huella de Numancia. Soria

Jimeno, A ; Morales, F; Trancho, G y López-Bueis, I (1996): Ritual y dieta alimenticia: la necrópolis celtibérica de Numancia, Numantia vol. 6, 31-44
Jimeno, A; de la Torre, J.I y Chain, ( 2010): "Ritos funerarios y mitos astrales en las necrópolis celtibéricas del Alto Duero", en F. Burillo (ed). Ritos y Mitos. VI Simposio sobre Celtíberos, 369-390. Soria

Kurtz, W.S (1987): La necrópolis de Las Cogotas. Ajuares Vol I. B.A.R. International Series.

Lorrio, A (1990): “La Mercadera (Soria): organización social y distribución de la riqueza en una necrópolis celtibérica" in F. Burillo (ed) Necrópolis celtibéricas: II Simposio sobre los celtíberos. 39-50 . Daroca, Zaragoza

Lorrio, A ( 1997): Los Celtíberos. Complutum Extra 7 , Alicante. Universidad Complutense-Universidad de Alicante

Lorrio, A (2001): "Los celtíberos", en M. AlmagroGorbea, M. Mariné, y J. Álvares-Sanchís (eds), Celtas y Vettones. Ávila: 183-200

Lorrio, A. y Ruiz-Zapatero, G. (2004): "The Celts in Iberia: An Overview" en M. Alberro y B. Arnold (eds): The Celts in the Iberian Peninsula, e-Keltoi. Journal of Interdisciplinary Celtic Studies. volume 6 :167-254

Lorrio, A Y Sánchez de Prado, Ma D (2009): La necrópolis celtibérica de Arcóbriga, en Caesaraugusta 80.

Lucy, S. J. (1997): "Housewives, Warriors and Slaves? Sex and Gender in Anglo-Saxon Burials", en J.Moore and E. Scott (eds.), Invisible people and processes: Writing Gender and Childhood into European Archaeology: 150-168. London

Marco Simón, F (2004): "Religion and Religious practices of the ancient Celts of the Iberian Peninsula", en M. Alberro and B. Arnold (eds): The Celts in the Iberian Peninsula, e-Keltoi. Journal of Interdisciplinary Celtic Studies. volume 6, 287-346

Martín Valls, R (¡986-87): “La segunda Edad del Hierro: consideraciones sobre su periodización", Zephyrus XXXIX-XL: 59-86

Martín Valls, R. (1999): "La Edad del Hierro", en J.L. Martín (ed) Historia de Salamanca I. Prehistoria y Edad Antigua. Salamanca, 123-217

Martínez J..P; Berzosa, R. de la Torre, J. I. y Jimeno, A ( 2005): "'Las necrópolis del Alto Duero, en A. Jimeno (Ed). Celtíberos.Tras la estela de Numancia. Soria, 245-252

Olmo Enciso, L (2012): "De Celtiberia a Santabariyya: La gestación del espacio y el proceso de formación de la sociedad andalusí (ss.VIII-IX)", en 711. Arqueología e Historia. Entre dos mundos, Zona Arqueológica 17. 
Prados Torreira, L. (2007): "Mujer y espacio sagrado: haciendo visibles a las mujeres en los lugares de culto de época ibérica”, en M. Sánchez Romero, M. (ed.), Arqueología de las mujeres y de las relaciones de género, Complutum, 18. 217-225.

Prados Torreira, L ( 2010 a): "La mujer aristocrática en el paisaje funerario ibérico", en T. Chapa e I. Izquierdo (eds.), La Dama de Baza. Un viaje femenino al más allá, Ministerio de Cultura, Madrid: 223-242.

Prados Torreira, L ( 2010b) : "Gender And Identity in Iberian funerary Contexts (5th-3rd century BC)", in Dommasnes, L. H., Hjorungdal, T., Montón, S., Sánchez Romero, M. y Wicker, N. L. (eds.), Situating Gender in European Archaeologies, Budapest, Archaeolingua: 205-224.

Prados Torreira, L (2012): "Si las muertas hablaran... Una aproximación a los contextos funerarios de la Cultura Ibérica", en L. Prados Torreira (Ed), Arqueología funeraria desde una perspectiva de género. Madrid, Ed. UAM: 233-256

Quesada Sanz, F. (1997): El armamento ibérico. Estudio tipológico, geográfico, funcional, social y simbólico de las armas en la Cultura Ibérica (siglos VI-I a. C.), Monographies Instrumentum, 3, Montagnac, Ed, Monique Mergoil.

Quesada Sanz, F (2010) : "Las armas de la sepultura 155 de la necrópolis de Baza", en T. Chapa, e I. Izquierdo (eds.), La Dama de Baza. Un viaje femenino al más allá, Ministerio de Cultura, Madrid. 149-170.

Quesada Sanz, F. (2012): "Mujeres, amazona, tumbas y armas: una aproximación transcultural" en L. Prados Torreira (Ed), Arqueología funeraria desde una perspectiva de género. Madrid, Ed. UAM: 317-364.

Rísquez, C. y García Luque, M. A. (2007): ¿Actividades de mantenimiento en el registro funerario? El caso de las necrópolis iberas, en P. González Marcén, et alii (eds.), Interpreting household practices: reflections on the social and cultural roles of maintenance activities, Treballs d'Arqueología, 13: 147-173.

Rísquez, C. y García Luque, M. A. (2012): "Identidades de género y prácticas sociales en el registro funerario ibérico. La necrópolis de El Cigarralejo" en L. Prados Torreira (Ed), Arqueología funeraria desde una perspectiva de género. Madrid, Ed. UAM: 257-276.

Ruiz Zapatero, G y Álvarez-Sanchís, J.R. (1995): “Las Cogotas: Oppida and the roots of urbanism in the Spanish Meseta". B. Cunliffe, B. and S. Keay, S. (eds) Social Complexity and the Development of Towns in Iberia: From the Copper Age to the Second
Century $A D$. Proceedings of the British Academy 86. Oxford: Oxford University Press: 209-236.

Ruiz Zapatero, G y Lorrio, A.J. (1995): “La Muerte en el Norte Peninsular durante el Primer Milenio A.C". en R. Fábregas; F. Pérez and C. Fernández (eds) Arqueoloxía da Morte na Península Ibérica desde as Orixes ata oMedievo, Xinzo de Limia: 223-248.

Sagardoy, T y Chorda, M (2010): Ritos de comensalidad y delimitación del espacio funerario en la necrópolis de Herrería IV (Guadalajara)", en F. Burillo (ed). Ritos y Mitos. VI Simposio sobre Celtíberos: 205-212

Salinas, M (2010): "Mujer, épica y mito entre los celtíberos", en F. Burillo (ed). Ritos y Mitos. VI Simposio sobre Celtíberos: 205-212

Sánchez Moreno (1997): "La mujer en las formas de relación entre núcleos y territorios de la Iberia protohistórica.I Testimonios literarios", Espacio, Tiempo y Forma 10: 285-294

Sanz Mínguez, C (1997): Los Vacceos: Cultura y ritos funerarios de un pueblo prerromano del Valle medio del Duero.La necrópolis de Las Ruedas. Padilla del Duero (Valladolid). Valladolid

Sanz Mínguez, C y Velasco Vázquez, J. (2003): Pintia. Un "oppidum" en los confines orientales de la región vaccea. Investigaciones arqueológicas vacceas, romanas y visigodas (1999-2003). Universidad de Valladolid

Sanz Mínguez, C y Romero Carnicero, F. (2010): "Mujeres, rango social y herencia en la necrópolis vaccea de Las Ruedas, Pintia (Padilla del Duero/Peñafiel/Valladolid)", en F. Burillo (ed). Ritos y Mitos. VI Simposio sobre Celtíberos: 403-420

Sanz Mínguez, C; Romero Carnicero, F. y Górriz Gañán ,C (2010): "El vino en Pintia: Nuevos datos y lecturas", en F. Burillo (ed). Ritos y Mitos. VI Simposio sobre Celtíberos: 595-612

Sanz Mínguez, C y Martín Valls, R. ( 2004): “Los Vacceos", en Celtas y Vettones. Avila. 314-325

Sargadoy, T y Cerdeño, M.L. ( 2002): "Estado actual sobre la investigación de la Edad del Hierro en Guadalajara", Actas del Primer Simposio de Arqueología de Guadalajara, vol 2.341-370

Sanz Mínguez, C; Velasco Vázquez, J; Centeno Cea, I; Juan i Tresserras, J y Matamala, J.L. (2003): "Escatología vaccea: nuevos datos para su comprensión a través de la analítica de residuos" en C. Sanz Mínguez y J. Velasco (Eds): Pintia, un oppidum en los confines orientales de la región vaccea. Valladolid: $145-171$ 
Sopeña, G. ( 2004): "Celtiberian Ideologies and Religion”, en M. Alberro and B. Arnold (eds): The Celts in the Iberian Peninsula, e-Keltoi. Journal of Interdisciplinary Celtic Studies. volume 6: 347-410

Sopeña,G. (2010): "La ideología de la muerte en el ámbito celtibérico. Evidencias rituales y nuevas perspectivas", en F. Burillo (ed). Ritos y Mitos. VI Simposio sobre Celtíberos: 245-272

Sørensen M.L. (2000): Gender Archaeology, Polity, London

Torija, A; Baquedano, I y Cruz, M (2010): "Inhumaciones infantiles en el centro peninsular durante la Protohistoria. Algunas novedades en el yacimiento de Cerrocuquillo", en F. Burillo (ed). Ritos y Mitos. VI Simposio sobre Celtíberos:434-444
Trancho, G. y Robledo, B (2010): "La Dama de Baza: análisis paleoantropológico de una cremación ibérica", en T. Chapa e I. Izquierdo (eds.), La Dama de Baza. Un viaje femenino al más allá, Ministerio de Cultura: 119-136. Madrid

Voss, B.L. (2008): "Sexuality Studies in Archaeology", Annual Review of Anthropology vol 37: 317-336 
